\title{
Endoscopic Killian-Jamieson diverticulotomy using a scissor-type electrosurgical knife
}

Killian-Jamieson diverticulum (KJD) is a rare, true esophageal diverticulum. Unlike the more common Zenker's diverticulum that arises on the posterior wall above the cricopharyngeus muscle, a KJD originates on the anterolateral wall of the cervical esophagus below the cricopharyngeal muscle [1]. The literature on endoscopic therapy for symptomatic KJD is limited [2-4].

We report a case of a 71-year-old woman who presented with a 6-month history of globus sensation, progressive dysphagia, and regurgitation of undigested food. A barium swallow revealed a 25 -mm diverticulum on the anterolateral aspect of the esophagus, consistent with a KJD ( $\triangleright$ Fig.1). The patient declined surgery and opted for endoscopic therapy.

During endoscopy, the KJD, with food debris within its lumen, was identified in the cervical esophagus. A transparent distal attachment cap (Olympus America, Center Valley, Pennsylvania, USA) was placed at the end of the endoscope and used to correctly identify the septum between the KJD and the true esophageal lumen. Next, a scissor-type endoscopic submucosal dissection (ESD) knife (Clutch Cutter; Fujifilm, Tokyo, Japan) was advanced through the working channel of the endoscope ( $\mathbf{F i g . 2 a}$ ). The septum was approached with the open serrated jaws of the scissor-type knife, which was then used to selectively grasp and cut the muscle fibers using electrocautery (Endocut Q mode [effect 2, duration 3, interval 1]; VIO 300D, ERBE, Tübingen, Germany) ( $\mathbf{F i g . 2} \mathbf{b}$; - Video 1). There were no intraprocedural complications. The incision line was apposed by the placement of four endoscopic clips.

The patient progressed well following the procedure and was able to tolerate liquids within 24 hours. A post-procedural computed tomography (CT) esopha-
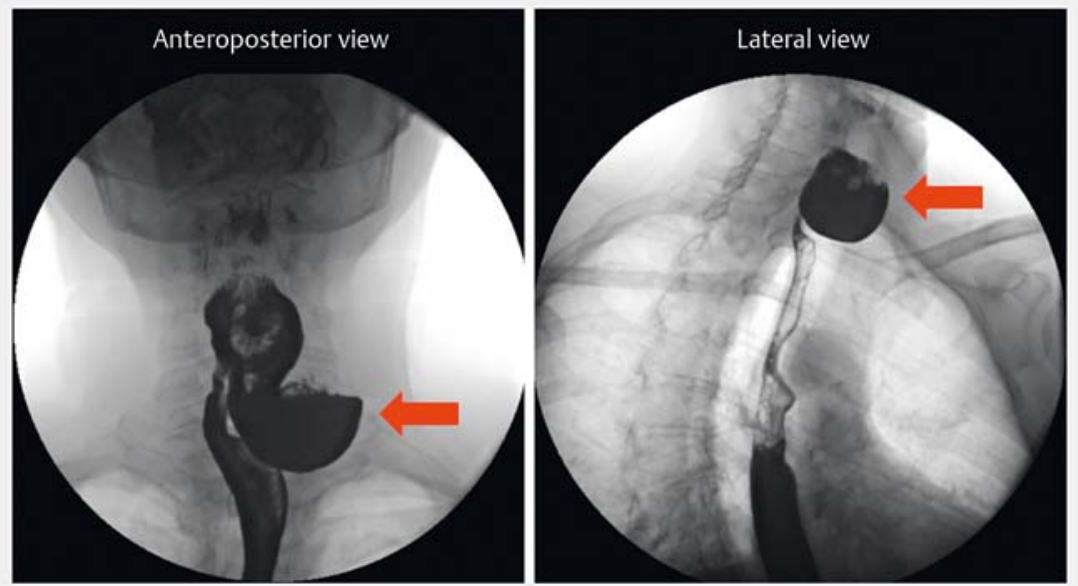

- Fig. 1 Barium swallow showing retained oral contrast within the Killian-Jamieson diverticulum (arrows) on anteroposterior and lateral views.
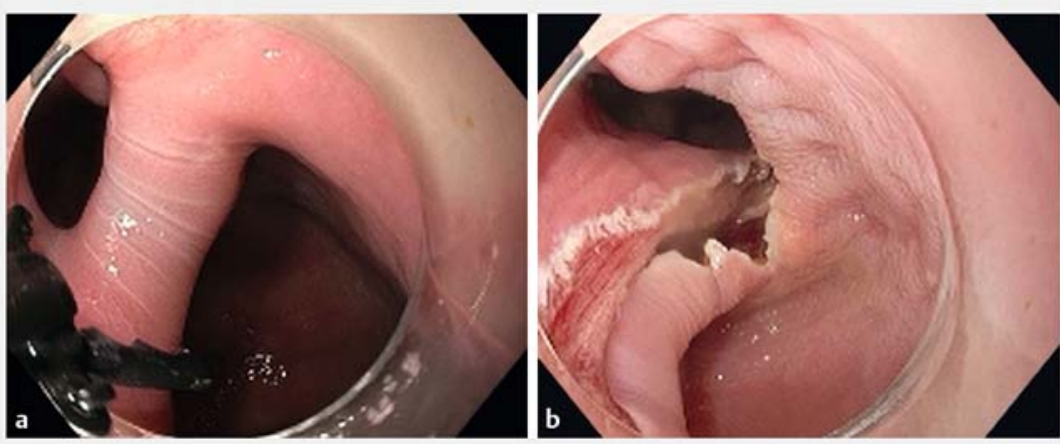

- Fig. 2 Endoscopic views showing: a the septum of the Killian-Jamieson diverticulum being approached by the scissor-type electrosurgical knife; $\mathbf{b}$ the appearance after completion of endoscopic diverticulotomy using the scissor-type electrosurgical knife.

gram confirmed the absence of any extraluminal oral contrast leak. The patient subsequently moved onto a regular diet and has remained asymptomatic for 10 weeks following the procedure.

A KJD is an unusual form of esophageal diverticulum that can present with symptoms similar to those of a Zenker's diverticulum. In this case, endoscopic myotomy was safely and effectively completed with a scissor-type ESD knife.

Endoscopy_UCTN_Code_TTT_1AO_2AN

Competing interests

None 


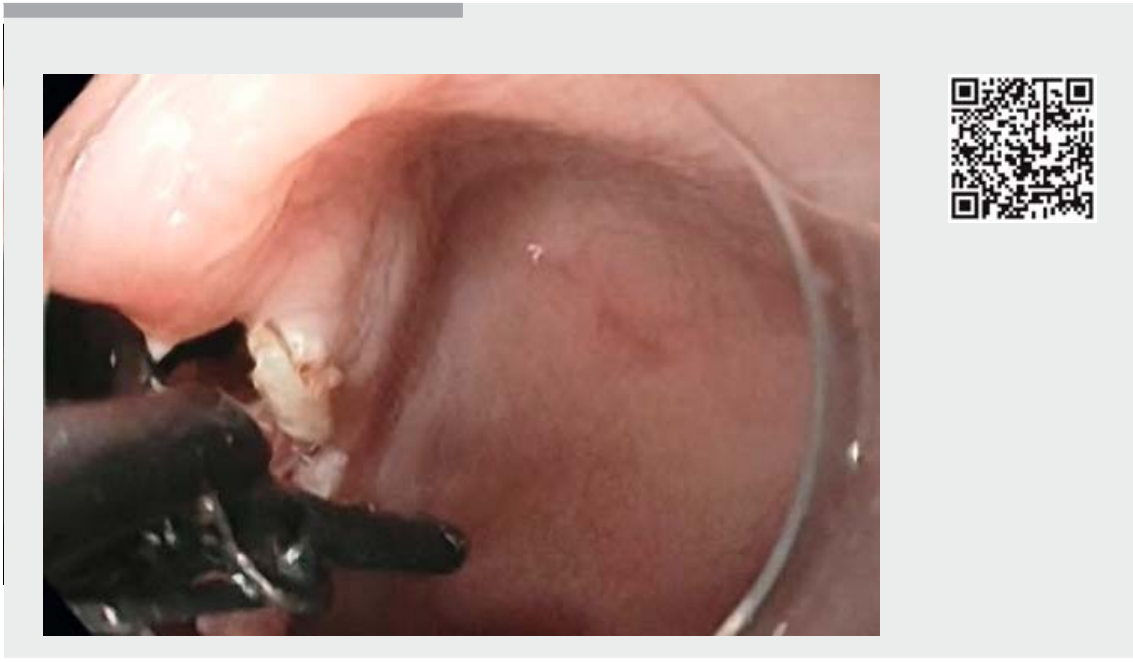

Video 1 Endoscopic Killian-Jamieson diverticulotomy using a scissor-type electrosurgical knife.

The authors

\section{Dennis Yang, Peter V. Draganov}

Division of Gastroenterology, Hepatology and Nutrition, University of Florida, Gainesville, Florida, USA

\section{Corresponding author}

\section{Peter V. Draganov, MD}

1329 SW 16th Street, Room \#5252,

Gainesville, FL 32608, United States of America

Fax: +1-352-627-9002

peter.draganov@medicine.ufl.edu

\section{Bibliography}

DOI https://doi.org/10.1055/a-0601-6467

Published online: 9.5.2018

Endoscopy 2018; 50: E175-E176

(c) Georg Thieme Verlag KG

Stuttgart · New York

ISSN 0013-726X

\section{ENDOSCOPY E-VIDEOS \\ https://eref.thieme.de/e-videos}

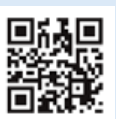

Endoscopy E-Videos is a free access online section, reporting on interesting cases and new techniques in gastroenterological endoscopy. All papers include a high quality video and all contributions are freely accessible online.

This section has its own submission website at https://mc.manuscriptcentral.com/e-videos
[1] Little RE, Bock JM. Pharyngoesophageal diverticuli: diagnosis, incidence and management. Curr Opin Otolaryngol Head Neck Surg 2016; 24: $500-504$

[2] Tang S], Tang L, Chen E et al. Flexible endoscopic Killian-Jamieson diverticulotomy and literature review (with video). Gastrointest Endosc 2008; 68: 790-793

[3] Lee CK, Chung IK, Park JY et al. Endoscopic diverticulotomy with an isolated-tip needleknife papillotome (Iso-Tome) and a fitted overtube for the treatment of a Killian-Jamieson diverticulum. World J Gastroenterol 2008; 14: 6589-6592

[4] Shahzad G, Changela K, Iqbal S. Killian-Jamieson diverticulum: a true esophageal diverticulum. Am J Gastroenterol 2016; 111: 1226 